\title{
Analysis of an automotive thermoelectric generator coupled to an electric exhaust heater to reduce NOx emissions in a Diesel-powered Euro VI Heavy Duty vehicle
}

\author{
A. Massaguer ${ }^{1}$, E. Massaguer ${ }^{1}$, J. Ximinis ${ }^{1}$, T. Pujol $^{1}$, M. Comamala ${ }^{1}$, L. Montoro ${ }^{1}$, J.R. Gonzalez ${ }^{1}$, \\ P. Fernández-Yañez ${ }^{2}, \mathrm{O}$. Armas ${ }^{2}$ \\ ${ }^{1}$ Department of Mechanical Engineering and Industrial Construction \\ E.P.S., Universitat de Girona \\ Campus de Montilivi-C/ Universitat de Girona, 4, 17003 Girona (Spain) \\ Phone/Fax number:+0034 9724184 89, e-mail: eduard.massaguer@udg.edu
}

\begin{abstract}
${ }^{2}$ Universidad de Castilla-La Macha. Campus de Excelencia Internacional en Energía y Medioambiente. Escuela de Ingeniería Industrial y Aeroespacial de Toledo. Av. Carlos III, s/n. 45071. Campus Fábrica de Armas, Toledo (Spain).
\end{abstract}

\begin{abstract}
This study presents a new approach to minimize the amount of NOx emitted by diesel engines of Heavy-Duty Vehicles during low engine regimes and low gases temperature conditions. We propose the addition of an electric Exhaust Gas Heater (EGH) to make the SCR system inject the urea solution at low engine regimes. The second part of this study focuses on the viability to use an Automotive Thermoelectric Generator (ATEG) to generate the energy required by the EGH and thus avoiding the need to consume electrical energy from the vehicle's system. This EGHATEG system is designed to be energetically closed, so there is no extra consumption of fuel. Experimental results show that NOx emissions reduce up to $80 \%$ when an EGH is added to a standard diesel-powered Euro VI Heavy Duty truck configuration. Simulations show that an ATEG installed downstream of the aftertreatment system can produce the energy required by the EGH. This system can improve SCR efficiency up to 55\% during low engine regimes.
\end{abstract}

Key words. Thermoelectric generator; catalyst efficiency; NOx reduction; Heavy Duty vehicle; SCR efficiency; ATEG

\section{Introduction}

A large proportion of buses and trucks operating in the EU's urban areas are still diesel-powered. In addition, many of them are not yet close to the end of their life. They suffer from generation of gas pollutants, particularly oxides of nitrogen (NOx), which are facing increasingly severe emission regulations.

However, these vehicles may be retrofitted with efficient exhaust after-treatment devices. Several systems allow high NOx reduction such as EGR (Exhaust Gas Recirculation), NOx absorbers, lean NOx catalyst systems and SCRs (Selective Catalytic Reduction).

SCR works as an advanced active emissions control that converts nitrogen oxides (NOx) into diatomic nitrogen (N2) and water $(\mathrm{H} 2 \mathrm{O})$ with the aid of a catalyst. A reducing agent, a solution of urea (32.5\%) and distilled commonly known as AdBlue, is needed to achieve this conversion reaction. This urea solution is decomposed into water vapor and ammonia that is adsorbed on the catalyst substrate as it is injected before SCR. Finally, adsorbed ammonia reacts with NOx and is reduced into harmless water vapor and nitrogen.

Recent research has remarked that this process strongly depends on temperature. Ammonia process reaction generally starts from $180^{\circ} \mathrm{C}$, reaching its maximum reaction rate around $350^{\circ} \mathrm{C}$. When exhaust gas temperature is lower than $180^{\circ} \mathrm{C}$, urea decomposition reaction can generate derivatives such as cyanuric acid, biuret, melamine, ammelide and ammeline as deposits on pipe wall, which are highly undesired for impeding the regular flow of gases. In order to avoid by-products, urea injection generally starts when exhaust gas temperature is higher than $180^{\circ} \mathrm{C}$.

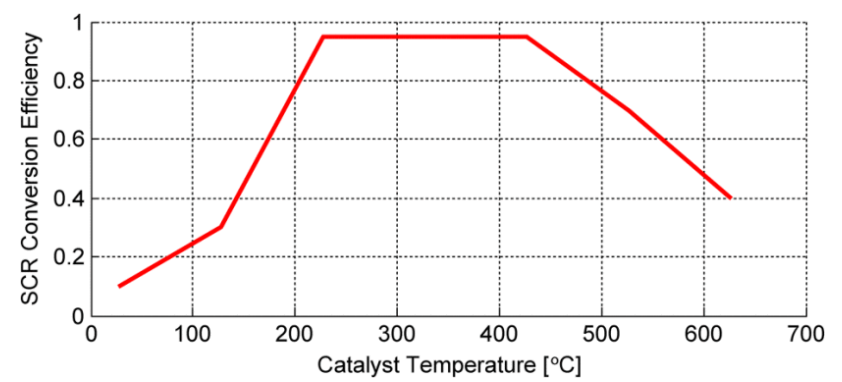

Figure 1. SCR conversion efficiency as a function of catalyst temperature.

Figure 1 is a static map of SCR efficiency. In order to achieve maximum de-NOx efficiency (around 0.95) the catalyst requires temperatures over $230^{\circ} \mathrm{C}$. This paper is focused on the first step of this heating process, reducing the time to achieve the proper target temperature when the 
urea solution is injected into the conversion system. This low temperature range (up to $130^{\circ} \mathrm{C}$ ) can be found at engine starts, during interurban routes or in vehicle operation modes with minor engine loads. SCR efficiency is also affected by ammonia storage and injection control of urea solution, both out of our scope.

Heavy Duty Vehicles (HDVs) for local freight transport, municipal vehicles and delivery vans are often driven for only short distances or through frequently interrupted routes. Under these driving conditions, these engines may not achieve the minimum exhaust gas temperature required to cut nitrogen oxide emissions effectively with conventional SCR systems. Gao et al., demonstrated that more than $50 \%$ of exhaust gas emissions, in a given driving cycle, are emitted during cold starts.

Hybrid Electrical Vehicles (HEVs) also face the challenge of high NOx emissions, as its internal combustion engine are commonly switched off at low speed and wheel torque, when the brake specific fuel consumption is especially high. Hybrid diesel buses present higher NOx values compared to full diesel buses. The poor SCR efficiency in HEVs is a consequence of low exhaust gas temperatures. Recent studies demonstrated that NOx emissions can increase around $30 \%$ for hybrid powertrains in urban real-life cycles. Therefore, the thermal management of the catalyst is fundamental for both HEVs and conventional vehicles.

This study explores the viability of using an Automotive Thermoelectric Generator (ATEG) coupled to an Exhaust Gas Heater (EGH) to reduce NOx emissions in HDVs. The EGH will make use of previously stored electrical power to heat the exhaust gases upstream of the SCR, in order to shorten the time that AdBlue is injected and reduce NOx emissions. The proposed system can be retrofitted in any Euro VI truck. This means that it can be installed without the need of replacing the existing aftertreatment system. This EGH-ATEG system is designed to be energetically closed, so there is no extra consumption of fuel.

The objective of this study is twofold; first, to experimentally validate the hypothesis that an EGH can reduce NOx emissions in a HDV; and secondly, to theoretically validate that the system can work energetically independent of the vehicle through the use of an ATEG.

\section{System proposed}

As stated before, the proposed system to reduce NOx emissions consists in a combination of the standard vehicle parts and specific added components such as an EGH. In this first approach, we will focus particularly on each part assembled downstream the exhaust pipe. This system is designed to work in two different stages illustrated in Figure 2.

Heating stage (1): this first step consists on rising the exhaust gas temperatures using the EGH. This device, an electrical resistance, consumes power from an dedicated electrical battery. The goal of this phase is to increase the exhaust gas temperature at SCR inlet. The beginning of this stage is when the engine starts as exhaust gases are on its lowest temperature level. The duration of this stage is determined by the target temperature $\left(=180^{\circ} \mathrm{C}\right)$, being around 12 minutes at idling in this tested vehicle using its standard exhaust system. Reaching this target temperature $\left(=180^{\circ} \mathrm{C}\right)$ is crucial because at this point urea solution is dosed into the system and its catalyst reaction is made properly, obtaining a faster and more efficient NOx reduction.

Recovery stage (2): this second step is related to ATEG conversion of thermal energy from exhaust gases into electricity. This electrical power is managed by the electronic control that stores it into the dedicated battery. This step starts when the engine is turned on and it can last up to 240 minutes (by assuming a maximum continuous driving time limited to 4 hours). The objective of this second phase is to maximize the amount of electrical energy stored for its later use by the EGH under low engine regime conditions.

Regarding the exhaust gas flow, each component of the proposed system is specifically located in order to optimize its functionality. If we begin upstream in the exhaust system, and after the turbocharger, we find the EGH. This component is located just before the standard SCR and DPF (Diesel Particle Filter) package of the vehicle. This standard lot of components includes the urea dosing system, not represented in Figure 2, and they are explained in the following section. The specific location of the EGH is important as it will maximize its impact into the standard NOx reduction system by providing a rise in temperature with minimal thermal loss. On the outlet side of the standard SCR-DPF package there is a bypass represented by a bifurcation of the exhaust pipe. Its function is to avoid high exhaust gas temperatures that damage the ATEG thermoelectric modules. Figure 2 represents an external solution that uses electrical valves to modulate the gas flow. However, Massaguer et al. have also developed an internal solution proven to succeed in its aim [1], [2]. The ATEG is located at the end of the exhaust system. It is important to be downstream of SCR as ATEG reduces the temperature of the exhaust gases and SCR needs a high temperature in order to perform efficiently. Furthermore, ATEG thermal loss will be reduced as post SCR catalytic converters rise exhaust gas temperature when performing.

The objective of obtaining emissions reduction without adding extra fuel consumption requires a compromise between energy consumed and produced. This system operates in two stages, as explained before. Heating stage (1) and recovery stage (2) are represented in Figure 2 by its energy flow respectively. In the first stage, the control unit feeds the EGH with the energy stored in the battery. In the second stage, the control unit feeds the battery with the energy recovered by the ATEG. ATEG requires a cold focus, then the thermal scheme is complemented with a cooling circuit composed by a low temperature heat exchanger and a water pump (not represented in Figure 2). 


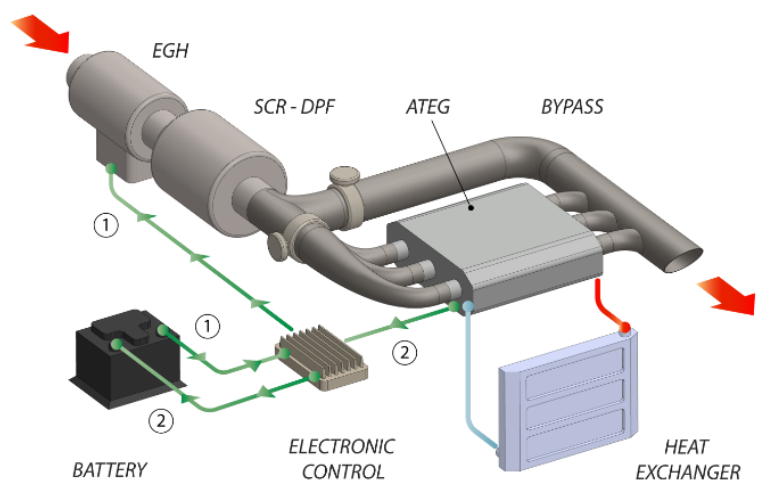

Figure 2. Proposed EGH-ATEG solution with the electrical energy flows: heating stage (1) and recovery stage (2).

Authors tested a similar ATEG, but at small-scale, in a lightduty vehicle with a maximum power production of $200 \mathrm{~W}$, a weight of $8 \mathrm{~kg}$ and a maximum backpressure of $10 \mathrm{mbar}$. They observed that the BP caused in the exhaust pipe did not adversely affect engine performance. A part form that, according to the fuel economy assessment method of ref. [2], the additional weight of the ATEG (i.e. generator and cooling system) only suppose an increase of $0.08 \%$ in fuel consumption. Considering that, both the backpressure and the additional weight added by the ATEG has been neglected.

\section{Experimental setup}

The system used consisted of an EGH located upstream of the standard aftertreatment system. The EGH is a Watlow ECOTEG unit with $12 \mathrm{~kW}$ of power. This device contains an electric heating coil controlled by a temperature regulation system designed specifically for this application. The whole system was disposed as seen in Figure 3.

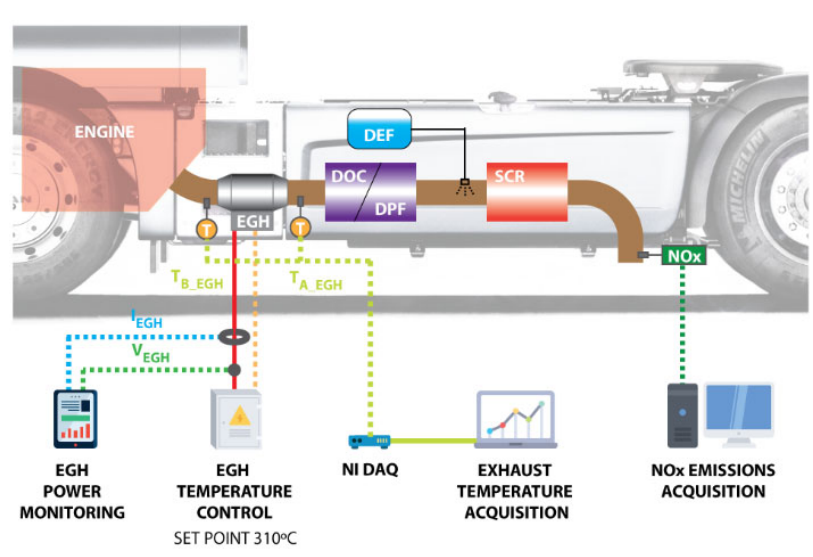

Figure 3. Scheme of emissions reduction system in tested vehicle.

The location of the EGH during the test can be seen in Figure 3, with minimal deviation of the original exhaust pipe in order to maintain the original vehicle design and to avoid gas flow alterations.
Two different stationary points were selected to conduct the study. The eleventh gear was selected to obtain all range of FTPP. Engine temperature was always below $90^{\circ} \mathrm{C}$ in order to keep the same engine conditions during the tests, simulating a cold start condition. A short period was held to reduce the engine temperature between tests. All regimes selected for this experiment, shown in Table I, can be found in a typical daily drive. NOx emissions were analysed under the following engine regimes and FTPPs.

Table I. - Stationary points selected for the tests.

\begin{tabular}{|c|c|c|c|}
\hline Test & $\begin{array}{c}\text { Engine } \\
\text { regime } \\
(\mathrm{rpm})\end{array}$ & FTPP $(\%)$ & $\begin{array}{c}\text { Vehicle } \\
\text { speed } \\
(\mathrm{km} / \mathrm{h})\end{array}$ \\
\hline 1 & 1000 & $30-90$ & 55 \\
\hline 2 & 1500 & $30-90$ & 82 \\
\hline
\end{tabular}

\section{Experimental results using an EGH}

This section presents a comparative analysis of NOx emitted by a standard HDV, with and without the use of a $12 \mathrm{~kW}$ EGH (see Table I). In all regimes, the target temperature of the $\mathrm{EGH}$ was set to $300^{\circ} \mathrm{C}$.

As it can be seen in Figure 4, at 1000 rpm, the NOx ppm values are the highest of the two regimes (Figures 5 and 6). NOx emissions, considering that EGH was disabled NOx $\boldsymbol{x}_{\text {EGH_oFF }}$, achieved $578 \mathrm{ppm}$ when the FTPP was at $60 \%$. At the same conditions, NOx measured with the EGH enabled $\boldsymbol{N O}_{\boldsymbol{O}} \boldsymbol{x}_{\boldsymbol{E} \boldsymbol{G} \text { _on }}$ was about $87 \mathrm{ppm}$. This was the maximum reduction achieved in all tests. In absolute numbers, it represented a NOx reduction of $508 \mathrm{ppm}$. In relative terms, however, the greatest reduction was achieved at 50\% FTPP with $97.2 \%$ of ppm reduction.

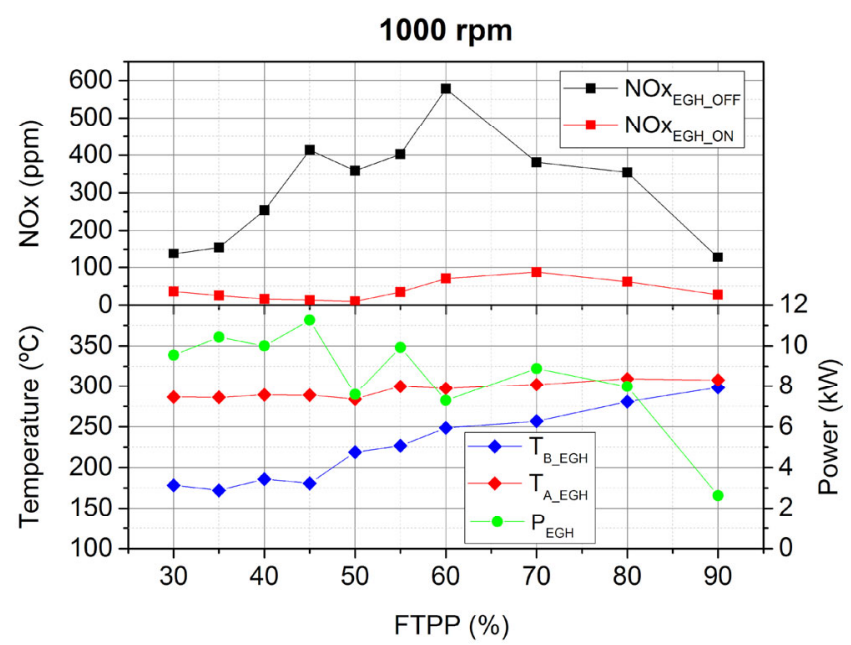

Figure 4. NOx emissions with EGH on and off (upper graph) and exhaust gas temperatures before and after

EGH with power consumed by EGH at $1000 \mathrm{rpm}$ $(\approx 55 \mathrm{~km} / \mathrm{h})$ (lower graph) as a function of the FTPP. Note that error bars are smaller than the size of the symbols. 


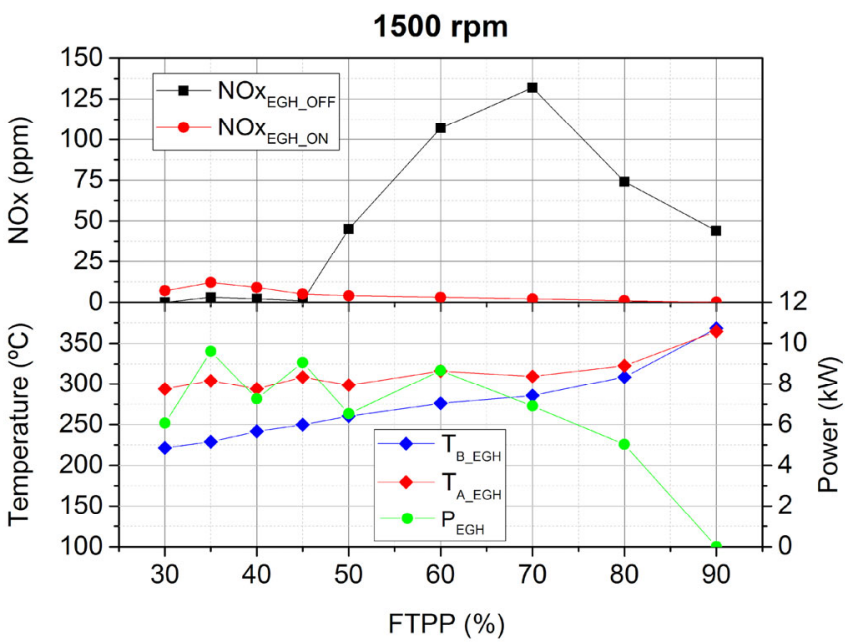

Figure 5. NOx emissions with EGH on and off (upper graph) and exhaust gas temperatures before and after EGH with power consumed by EGH at $1500 \mathrm{rpm}(\approx 82 \mathrm{~km} / \mathrm{h})$ (lower graph) as a function of the FTPP. Note that error bars are smaller than the size of the symbols.

Figure 5 shows the stationary points at $1500 \mathrm{rpm}$. It can be observed that the contribution of the EGH was minimal along the first FTPP points. This can be explained by the EGR valve aperture at the $30 \%-45 \%$ FTPP that cut NOx emissions through the reinjection of the exhaust gases into the admission port. ECU controls this valve position. On the other hand, it was at FTPP values higher than $45 \%$ when the EGH contribution was relevant. A $\boldsymbol{N O} \boldsymbol{x}_{\boldsymbol{E} \boldsymbol{G} \boldsymbol{H}_{-} \boldsymbol{O} \boldsymbol{F} \boldsymbol{F}}$ peak point of $132 \mathrm{ppm}$ at $70 \%$ FTPP was observed. These NOx emissions $\boldsymbol{N O}_{\boldsymbol{E} \boldsymbol{G H} \boldsymbol{O} \boldsymbol{O N}}$ were reduced up to $98.48 \%$ through the use of the EGH.

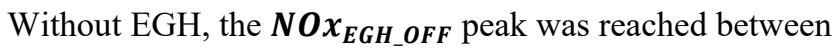
$60-70 \%$ FTPP. However, thanks to the inclusion of the $\mathrm{EGH}$, the urea solution injection threshold was reached earlier. Consequently, the earlier catalytic conversion provided a dramatic descend of $\boldsymbol{N O} \boldsymbol{O x}_{\boldsymbol{E} \boldsymbol{G} \boldsymbol{H}_{-} \boldsymbol{O N}}$.

\section{SCR efficiency vs EGH power consumption}

Test 1 scenario will be used for this theoretical approach due to its low engine regime (1000 rpm) and its low gas temperatures that reflect a typical low speed route done by a HDV. Selected FTPP values are in the low range $(30 \%$ 45\%) because it is where the $\boldsymbol{T}_{\boldsymbol{B} \boldsymbol{S} \boldsymbol{S} \boldsymbol{C} \boldsymbol{R}}$ are lower than the urea solution threshold $\left(\mathrm{T}<180^{\circ} \mathrm{C}\right)$. Data in Table II contains a SCR inlet gas temperature comparison between the standard system (EGH disabled), the same system with the EGH enabled, and a proposed EGH. This last group of gas temperatures is calculated using the heat transfer equation $\boldsymbol{P}_{\boldsymbol{E} G \boldsymbol{H}}=\dot{\boldsymbol{m}} \boldsymbol{c}_{\boldsymbol{p}}\left(\boldsymbol{T}_{\boldsymbol{A}_{-} \boldsymbol{E} G \boldsymbol{H}}-\boldsymbol{T}_{\boldsymbol{B}_{-} \boldsymbol{E} G \boldsymbol{H}}\right)$ by assuming that all electrical power supplied to the EGH is effectively transferred to the exhaust gases in terms of heat. In the previous equation, $\boldsymbol{P}_{\boldsymbol{E G H}}$ is the proposed power of the EGH, $\dot{\boldsymbol{m}}$ is the measured exhaust gas mass flow rate at a constant FTPP, $\boldsymbol{c}_{\boldsymbol{p}}$ is the specific heat at constant pressure of the exhaust gases calculated using the temperature value registered for each FTPP, and $\boldsymbol{T}_{\boldsymbol{B}_{-} \boldsymbol{E} \boldsymbol{G} \boldsymbol{H}}$ is the measured exhaust gas temperature before the EGH at a constant FTPP. As seen in Chapter 3, the SCR is installed downstream the EGH. For this reason, we consider $\boldsymbol{T}_{\boldsymbol{A}_{-} \boldsymbol{E} \boldsymbol{G} \boldsymbol{H}}=\boldsymbol{T}_{\boldsymbol{B}_{-} \boldsymbol{S C R} \boldsymbol{R}}$. Table II shows the SCR efficiency improvements under different values of $\boldsymbol{P}_{\boldsymbol{E} \boldsymbol{G} \boldsymbol{H}}$, ranging between 0.5 and $5 \mathrm{~kW}$.

Table II. - SCR efficiency for different EGH powers at $1000 \mathrm{rpm}$.

\begin{tabular}{|c|c|c|c|c|c|c|}
\hline \multirow{2}{*}{ 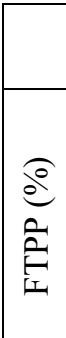 } & \multicolumn{3}{|c|}{$\begin{array}{l}\text { SCR inlet temperature } \\
\left(T_{B_{-} S C R}\right)\end{array}$} & \multicolumn{3}{|c|}{$\begin{array}{c}\text { SCR conversion } \\
\text { efficiency }\end{array}$} \\
\hline & 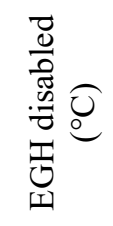 & 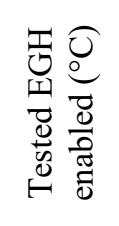 & 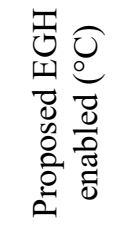 & 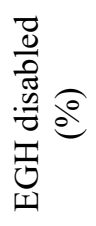 & 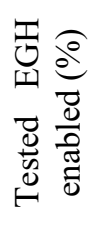 & 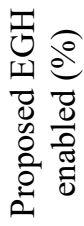 \\
\hline \multicolumn{7}{|c|}{ EGH proposed of $0.5 \mathrm{~kW}$} \\
\hline 30 & 178.27 & 286.41 & 183.94 & $64 \%$ & $95 \%$ & $67 \%$ \\
\hline 35 & 172.15 & 286.1 & 177.63 & $60 \%$ & $95 \%$ & $63 \%$ \\
\hline 40 & 185.9 & 289.13 & 191.09 & $68 \%$ & $95 \%$ & $72 \%$ \\
\hline 45 & 180.7 & 288.82 & 185.58 & $65 \%$ & $95 \%$ & $68 \%$ \\
\hline \multicolumn{7}{|c|}{ EGH proposed of $1 \mathrm{~kW}$} \\
\hline 30 & 178.27 & 286.41 & 189.61 & $64 \%$ & $95 \%$ & $71 \%$ \\
\hline 35 & 172.15 & 286.1 & 183.11 & $60 \%$ & $95 \%$ & $67 \%$ \\
\hline 40 & 185.9 & 289.13 & 196.28 & $68 \%$ & $95 \%$ & $75 \%$ \\
\hline 45 & 180.7 & 288.82 & 190.46 & $65 \%$ & $95 \%$ & $71 \%$ \\
\hline \multicolumn{7}{|c|}{ EGH proposed of $2 \mathrm{~kW}$} \\
\hline 30 & 178.27 & 286.41 & 200.96 & $64 \%$ & $95 \%$ & $78 \%$ \\
\hline 35 & 172.15 & 286.1 & 194.07 & $60 \%$ & $95 \%$ & $74 \%$ \\
\hline 40 & 185.9 & 289.13 & 206.66 & $68 \%$ & $95 \%$ & $82 \%$ \\
\hline 45 & 180.7 & 288.82 & 200.21 & $65 \%$ & $95 \%$ & $78 \%$ \\
\hline \multicolumn{7}{|c|}{ EGH proposed of $3 \mathrm{~kW}$} \\
\hline 30 & 178.27 & 286.41 & 212.30 & $64 \%$ & $95 \%$ & $85 \%$ \\
\hline 35 & 172.15 & 286.1 & 205.04 & $60 \%$ & $95 \%$ & $81 \%$ \\
\hline 40 & 185.9 & 289.13 & 217.04 & $68 \%$ & $95 \%$ & $88 \%$ \\
\hline 45 & 180.7 & 288.82 & 209.97 & $65 \%$ & $95 \%$ & $84 \%$ \\
\hline \multicolumn{7}{|c|}{ EGH proposed of $4 \mathrm{~kW}$} \\
\hline 30 & 178.27 & 286.41 & 223.65 & $64 \%$ & $95 \%$ & $93 \%$ \\
\hline 35 & 172.15 & 286.1 & 216.00 & $60 \%$ & $95 \%$ & $88 \%$ \\
\hline 40 & 185.9 & 289.13 & 227.42 & $68 \%$ & $95 \%$ & $95 \%$ \\
\hline 45 & 180.7 & 288.82 & 219.72 & $65 \%$ & $95 \%$ & $90 \%$ \\
\hline \multicolumn{7}{|c|}{ EGH proposed of $5 \mathrm{~kW}$} \\
\hline 30 & 178.27 & 286.41 & 234.99 & $64 \%$ & $95 \%$ & $95 \%$ \\
\hline 35 & 172.15 & 286.1 & 226.96 & $60 \%$ & $95 \%$ & $95 \%$ \\
\hline 40 & 185.9 & 289.13 & 237.79 & $68 \%$ & $95 \%$ & $95 \%$ \\
\hline 45 & 180.7 & 288.82 & 229.48 & $65 \%$ & $95 \%$ & $95 \%$ \\
\hline
\end{tabular}


At this point it is important to remark that it is unnecessary to consume $12 \mathrm{~kW}$ in an EGH to substantially reduce NOx emissions. Considering temperature of urea solution injection around $180^{\circ} \mathrm{C}$, it is clear that the EGH device should only heat the exhaust gases up to reach this target value. To provide an extra thermal power to the exhaust gases is useless and counter-productive. The SCR efficiency reaches its maximum in the worst FTPP scenario of low exhaust gas temperatures with a $5 \mathrm{~kW}$ EGH.

In a conventional system, the power supplied as well as the energy consumed by the EGH must be extracted from the electrical system of the vehicle. The electrical power generated by the vehicle comes from the alternator, which converts part of the mechanical energy produced by the combustion engine into electricity. This means that a system with EGH to achieve an extra NOx reduction would demand more electrical energy. Hence, more time using the alternator would imply an increase on the vehicle's fuel consumption.

To avoid this emission increment, our research focuses on the viability of using the exhaust waste heat to produce the electricity needed for the EGH. The goal is to simulate and quantify an ATEG model to convert waste heat, downstream of the aftertreatment system, into electricity. This will avoid the need for the electric system to consume more fuel to produce the extra electrical energy. Many theoretical models [4] and experimental prototypes [5]-[7] have been developed which demonstrate the feasibility of automotive ATEGs. Other ways to produce this additional energy from exhaust gases may be the use of Organic Rankine Cycle (ORC).

\section{ATEG model}

In order to validate the previous exposed idea, a simulation model of an ATEG is launched with relevant data gathered during the experimental test described in section 3 . The idea is to explore the theoretical capabilities of commercial Thermoelectric Modules (TEM) disposed in a particular array that guarantees enough power to supply electrical energy to the EGH, see Figure 6. Focusing on this goal, a $1500 \mathrm{rpm}$ regime is chosen as it contains the highest tested exhaust gas temperatures without surpassing the TEM maximum working temperature $\left(230^{\circ} \mathrm{C}\right)$. ATEG benefits from these conditions to convert thermal energy into electricity for a future use in a low regime (for example $1000 \mathrm{rpm})$.

GT-SUITE is chosen as the simulation software due to its proven research in the automotive sector [8]. This multiphysics CAE simulation tool is a commonly used software for engine modelling, which also incorporates a TEG block in its library to model and size automotive thermoelectric generators for exhaust waste heat recovery.

Exhaust gas temperature and its mass flow rate are both variables depending on a particular FTPP value. It is important to keep in mind the most suitable location for an ATEG into the exhaust system of this particular vehicle. In order to minimize its influence, it is reasonable to install it downstream just after the DPF. This location allows us to conclude that the exhaust inlet temperature parameter introduced into the simulation is going to be the DPF outlet temperature obtained from the ECU during the experimentation. On the other hand, there are constant parameters introduced such as coolant mass flow rate $(0.12 \mathrm{~kg} / \mathrm{s})$ and coolant inlet temperature $\left(25^{\circ} \mathrm{C}\right)$. This cooling circuit relies on a water pump and a heat exchanger that provides a constant flow along the cold face of every TEM. Ambient temperature registered from the day of the experiment $\left(30^{\circ} \mathrm{C}\right)$ is introduced for the TEM initial temperature parameter.

The thermoelectric module used in the simulation was the TG-12-08 from Marlow Industries. This module uses bismuth telluride as a thermoelectric material. It was chosen because it has shown a high correlation between manufacturer's data and experimental data.
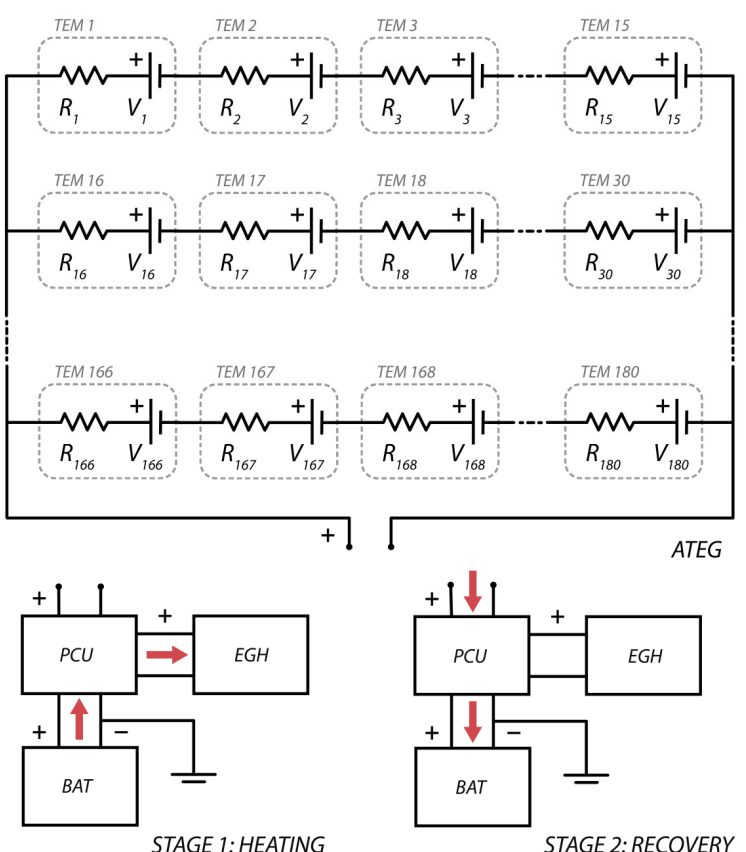

Figure 6. Simulated electrical scheme of system proposed. Includes ATEG with its TEM array, Heating stage (1) and Recovery stage (2) with its particular energy flow between battery, PCU, EGH and ATEG.

It is assumed that EGH is used the first 12 minutes after the engine start up. This time coincides with the cold start period for this particular vehicle. After this is time, the standard aftertreatment system of the vehicle starts cutting NOx emissions efficiently.

Figure 7 quantifies the SCR efficiency improvement of the proposed EGH+ATEG system respect to the standard aftertreatment system of the HDV tested, both cases compared at $1000 \mathrm{rpm}$ regime. Y-axis (time values in minutes) represents the duration of the recovery stage performed by the ATEG at $1500 \mathrm{rpm}$ regime. These results confirm that EGH is required in lower or medium FTPP values, where major improvements are achieved, especially at high power demand of EGH (4 kW - $5 \mathrm{~kW})$. Analysing results from high FTTP values to lower, we can 
see a progressive increase in SCR improvement, related with EGH power demand. From $65 \%$ FTPP onwards there is no remarkable efficiency improvement $(<1 \%)$ of the catalytic system. Even for an EGH proposed of $0.5 \mathrm{~kW}$, we can see that improvements in almost every FTTP can be dismissed. A poor efficiency improvement $(5 \%-15 \%)$ is obtained for FTPP downwards until $50 \%$ for most EGH power values. However, EGHs of $0.5 \mathrm{~kW}$ and $1 \mathrm{~kW}$ are included totally in this improvement zone or even lower. The next efficiency improvement zone is more dynamic, which represents major values obtained adding few extra minutes of the ATEG recovery stage. Observing this medium improvement zone $(15 \%-40 \%)$, we can conclude that includes low FTPP values $(30 \%-45 \%)$. EGH power demand required for these improvements is in the range of $2 \mathrm{~kW}$ to $3 \mathrm{~kW}$. The time needed to recover this energy through the ATEG is moderate (approximately 50-90 minutes). Moving on, we arrive to major recovery improvements (40\%-55\%). These figures can be obtained by EGH power values of $4 \mathrm{~kW}$ to $5 \mathrm{~kW}$ and can be applied for low FTTP values (30\%-45\%). Time figures for recovery stage of this power range are longer (95-155 minutes) but completely within HDV daily transportation routines.

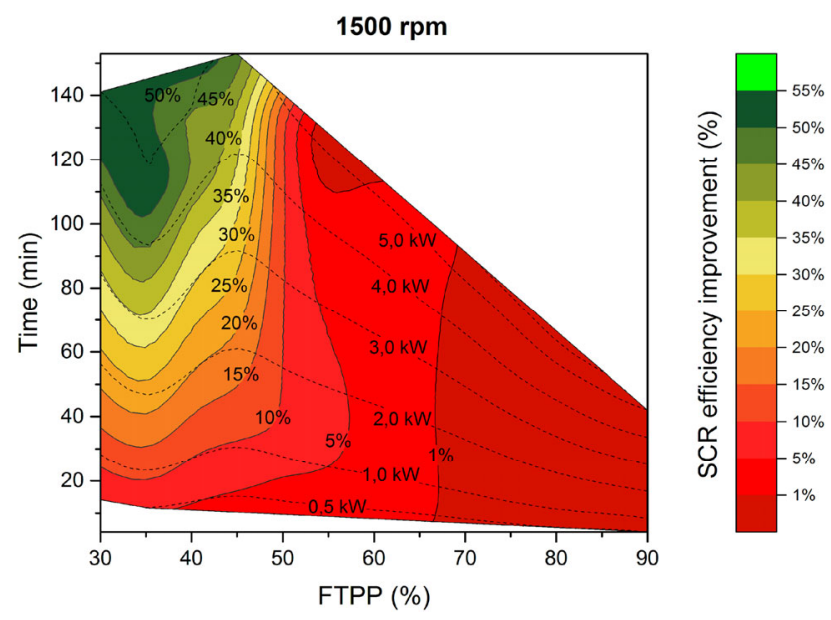

Figure 7. SCR efficiency improvement at $1000 \mathrm{rpm}$ using different EGH power. Time using ATEG at $1500 \mathrm{rpm}$ to supply respective EGH power demands at $1000 \mathrm{rpm}$.

\section{Conclusion}

This study experimentally demonstrates that the use of an EGH can reduce the NOx emissions more than $80 \%$ in a Diesel-powered Euro VI Heavy Duty truck working at low engine regimes. The highest reductions were achieved at $1000 \mathrm{rpm}$ and medium FTPP values. It also has been demonstrated that, at low engine regimes, EGH power higher than $5 \mathrm{~kW}$ does not produce a significant impact on NOx reduction. A conventional catalytic device heated using an EGH of $5 \mathrm{~kW}$ could improve the SCR efficiency from $65 \%$ to $95 \%$. Consequently, exhaust gas heaters are a potential solution to the high emitting low engine regimes issue.

Numerical simulation of an ATEG demonstrate the viability of using the exhaust waste heat to produce electricity needed by the EGH. This ATEG generates a power range between
$0.4 \mathrm{~kW}$ (at 30\% FTPP) and above $1.4 \mathrm{~kW}$ (at maximum FTPP of $90 \%$ ). These values are obtained using an average engine regime (1500 rpm) scenario.

The viability of energy supply during a cold start scenario (1000 rpm during 12 minutes) is positively demonstrated by time figures not exceeding of 155 minutes in the worst conditions ( $5 \mathrm{~kW}$ of EGH demand and generation at $45 \%$ FTPP). The EGH-ATEG allows the aftertreatment system to start dosing urea solution sooner. In consequence, the SCR efficiency is improved up to $55 \%$ using a proposed EGH of $5 \mathrm{~kW}$, which is powered exclusively by an ATEG.

\section{Acknowledgement}

Authors wish to thank the financial support received to the project RECOVER-TE Waste thermal energy recovery in light duty vehicles. Technological impact. Ref.: RTI2018095923-B-C21

\section{References}

[1] A. Massaguer, T. Pujol, M. Comamala, and E. Massaguer, "Feasibility study on a vehicular thermoelectric generator coupled to an exhaust gas heater to improve aftertreatment's efficiency in coldstarts," Appl. Therm. Eng., vol. 167, p. 114702, Nov. 2020, doi: 10.1016/j.applthermaleng.2019.114702.

[2] M. Comamala, A. Massaguer, E. Massaguer, and T. Pujol, "Validation of a fuel economy prediction method based on thermoelectric energy recovery for mid-size vehicles," Appl. Therm. Eng., vol. 153, pp. 768-778, 2019, doi:

10.1016/j.applthermaleng.2019.03.004.

[3] E. Massaguer, A. Massaguer, T. Pujol, M. Comamala, L. Montoro, and J. R. Gonzalez, "Fuel economy analysis under a WLTP cycle on a mid-size vehicle equipped with a thermoelectric energy recovery system," Energy, vol. 179, pp. 306-314, 2019, doi: 10.1016/j.energy.2019.05.004.

[4] E. Massaguer, A. Massaguer, T. Pujol, J. R. Gonzalez, and L. Montoro, "Modelling and analysis of longitudinal thermoelectric energy harvesters considering series-parallel interconnection effect," Energy, vol. 129, pp. 59-69, Jun. 2017, doi: 10.1016/j.energy.2017.04.061.

[5] M. Comamala, T. Pujol, I. R. Cózar, E. Massaguer, and A. Massaguer, "Power and Fuel Economy of a Radial Automotive Thermoelectric Generator: Experimental and Numerical Studies," Energies, vol. 11, no. 10, 2018, doi: 10.3390/en11102720.

[6] P. Fernández-Yañez, O. Armas, A. Capetillo, and S. Martínez-Martínez, "Thermal analysis of a thermoelectric generator for light-duty diesel engines," Appl. Energy, vol. 226, pp. 690-702, Sep. 2018, doi: 10.1016/j.apenergy.2018.05.114.

[7] S. Ezzitouni, P. Fernández-Yáñez, L. Sánchez, and O. Armas, "Global energy balance in a diesel engine with a thermoelectric generator," Appl. Energy, vol. 269, 2020, doi: 10.1016/j.apenergy.2020.115139.

[8] M. Comamala, I. R. Cózar, A. Massaguer, E. Massaguer, and T. Pujol, "Effects of design parameters on fuel economy and output power in an automotive thermoelectric generator," Energies, vol. 11, no. 12, p. 3274, Nov. 2018, doi: 10.3390/en11123274. 